\section{P16.20 BACTERIAL RESISTANCE OF STAPHYLOCOCCUS AUREUS ISOLATED FROM PEOPLE LIVING WITH HIVIAIDS A BRAZILIAN CITY}

LAF Reinato, DPM Pio, LP Lopes, FMV Pereira, Srms Canini, E Gir*. University of São Paulo at Ribeirão Preto College of Nursing (EERP-USP), WHO Collaborating Centre for Nursing Research Development. Ribeirão Preto (SP), Brazil

10.1136/sextrans-2015-052270.567

Introduction Staphylococcus aureus naturally colonises the skin and mucous membranes of humans, with the preferences of the nostrils. It represent an important pathogen for humans to cause a wide spectrum of diseases, including, skin diseases, soft tissues, bones, urinary tract and opportunistic infections, Staphylococcus aureus was one of the featured species. The production of penicillinase ( $\beta$-lactamase) by Staphylococcus aureus has been associated with resistance that these microorganisms have developed to penicillin, used for the first time in 1941. The aim of the study was to identify the resistance of Staphylococcus aureus to antibiotics in people living with HIV/AIDS.

Methods A cross-sectional was performed from August/2011 to July/2012, with people living with HIV/AIDS admitted in a reference institution in São Paulo State, Brazil. A swab Stuart was used to collect the nostril material, in the first day of admission and it was processed at the microbiology laboratory. For descriptive statistics, we used SPSS version 17.0.

Results Among the 169 participants $57.4 \%$ were men, age range from 40-49 years old, in 39.6\% were, white Ethnicity was predominant (63.9\%). We identified 46 Staphylococcus aureus which were resistant to the following antibiotics: penicillin (89.1\%), ampicillin (86.8\%), erythromycin (34.8\%) and oxacillin $(21.8 \%)$.

Conclusion Staphylococcus aureus is a pathogen of clinical importance, that may cause various infections. Prevention and control measures can be instituted to minimise the spread of this microorganism in the hospital and in the community, such as screening patients, specific actions to colonised or infected people and standard and contact precautions used by health professionals.

Disclosure of interest statement The above authors declare that they do not have any potential conflict of interest in this study.

\section{P16.21 WOMEN SEX WORKERS LIVING WITH HIV IN A CAPITAL OF NORTHEASTERN BRAZIL - PRELIMINARY RESULTS}

${ }^{1}$ RLB Magalhães, ${ }^{2}$ MTG Galvão, ${ }^{3}$ LAF Reinato, ${ }^{3}$ RK Reis, ${ }^{4}$ SA Teles, ${ }^{3} E$ Gir* ${ }^{*}$ Federal University of Piauí, Technical College of Teresina, Teresina (PI), Brazil; ${ }^{2}$ Department of Nursing, Federal University of Ceará, Fortaleza (CE), Brazil; ${ }^{3}$ University of São Paulo at Ribeirão Preto College of Nursing (EERP-USP), WHO Collaborating Center for Nursing Research Development. Ribeirão Preto (SP), Brazil; ${ }^{4}$ School of Nursing, Federal University of Goiás, Full Professor, Federal University of Goiás, Goiânia (GO), Brazil

\section{$10.1136 /$ sextrans-2015-052270.568}

Introduction The HIV epidemic is concentrated in large urban centres, with higher prevalence in most vulnerable populations. Methods Cross-sectional study aimed to characterise the female sex workers living with HIV, considering the sociodemographic and behavioural aspects. Conducted from January 2014 to February 2015 were recruited 417 female sex workers, using the Respondent Driven Sampling method (RDS). All were interviewed and tested using the rapid test for HIV. The study complied with the ethical aspects.
Results The age ranged from 23 to 47 years. In relation to schooling, four (33.3\%) reported being illiterate, only $1(8.3 \%)$ had completed high school. The monthly income ranged 1-2 wages equivalent to US\$252.5. Regarding marital status claim to be single, nine $(75 \%)$ reported having an affective stable partner out of prostitution and six (50\%) reported having paid fixed partnership in prostitution. About skin colour seven (58.3\%) consider themselves black; two (16.6\%) brown; three (25\%) white. Regarding the search for health service five women mark consultation near their homes; two look for the community health worker and five did not seek the health service. Regarding the use of condoms, it is not always used with a regular partner. Of all participants, 12 (2.9\%) were positive for anti-HIV, a prevalence seven times higher than that estimated for women in general in the country.

Conclusion A high HIV prevalence suggest the need to increase access of this population to health services, increase the testing offer to HIV and raise awareness of condom use in sexual relations independent of the type of sexual partnership.

Disclosure of interest statement The above authors declare that they do not have any potential conflict of interest in this study.

\section{P16.22 PREVALENCE AND EPIDEMIOLOGY OF CO-INFECTION HIV/TUBERCULOSIS IN A BRAZILIAN CITY}

E Gir*, CC Castrighini, RK Reis, LAS Neves. School of Nursing, University of São Paulo, RibeirãoPreto-SP, Brazil

\section{$10.1136 /$ sextrans-2015-052270.569}

Background This study aimed to evaluate the prevalence and epidemiology of co-infection HIV/tuberculosis, in the period from 2003 to 2011, reported the city of São Paulo, Brazil.

Methods This is a cross-sectional, retrospective study. Data were derived from the linkage between regional database of tuberculosis (TBweb) and national banks of AIDS (SINAN SISCEL and SICLOM), which contains data from the compulsory notification of these diseases. The procedure of relationship data was performed by RecLink III software and analysed using the Statistical Package for Social Sciences (SPSS) version 17.0 for Windows. The study was approved by the Research Ethics and obtained authorisation the use of data.

Results The study included 1,277 cases of tuberculosis, of which 338 had an HIV/tuberculosis, showing a prevalence of $26.5 \%$. With regard to demographic variables, 244 (72.2\%) were male, between 35-44 years (45.0\%) and 151 (44.7\%) white. Regarding the type of case, 308 (91.1\%) were new and most individuals (58.9\%) achieved cure. The most frequent clinical form was pulmonary in $201(59.5 \%)$ cases. Regarding the $\mathrm{CD}^{+}{ }^{+} \mathrm{T}$ lymphocyte count, 189 (55.9\%) had lower rates than 200 cells $/ \mathrm{mm}^{3}$ of blood and $102(30.2 \%)$ had viral load between 1,001 and 100,000 copies.

Conclusions The study demonstrates the importance of HIV/TB coinfection in this county. In this sense, it stands out the need for public health efforts for the prevention and early diagnosis of HIV using HIV testing and counselling, as well as the active search for symptomatic tuberculosis.

Disclosure of interest statement The above authors declare that they do not have any potential conflict of interest in this study. 